\title{
Casa: um ritmo da memória em Alma, de Manuel Alegre
}

\author{
House: a rhythm of the memory in Alma, by Manuel Alegre
}

\author{
BRUNO MAZOLINI DE BARROS
}

Pontifícia Universidade Católica do Rio Grande do Sul. Porto Alegre, RS, Brasil.

Resumo: Partindo da configuração do próprio romance, assim como de duas indicações da fortuna crítica, o presente texto propõe analisar o protagonismo do espaço da casa, assim como suas significações, no romance Alma (1995), de Manuel Alegre. Para tanto, passagens do texto são confrontadas principalmente com propostas que postulam a casa como local central na experiência do sujeito: as de Otto Friedrich Bollnow, em $O$ homem e o espaço; e as de Gaston Bachelard, em A poética do espaço e em A terra e os devaneios do repouso: ensaio sobre as imagens da intimidade.

Palavras-chave: Literatura portuguesa; Romance português; Casa.

Abstract: Considering the configuration of the novel itself and indications on two essays of literary criticism, this paper intends to analyse the importance of the space of the house, as well as its significations, in the novel Alma (1995), by Manuel Alegre. For this, passages of the text are confronted mainly with proposals that postulate the house as a central place in the individual's experience, such The Human Space, by Otto Friedrich Bollnow; and The Poetics of Space and Earth and Reveries of Repose: An Essay on Images of Interiority, by Gaston Bachelard.

Keywords: Portuguese literature; Portuguese novel; House.

Uma das provas da realidade da casa imaginária é a confiança que tem um escritor de nos interessar pela recordação de uma casa da própria infância.

GASTON BACHELARD, A terra e os devaneios do repouso.

E respirava o ar de todas as viagens, da minha janela, capital do Mundo, debruçado sobre o largo onde começavam todos os caminhos.

Manuel Alegre,

"Rosas vermelhas", em Praça da Canção. 
Em Alma, romance de Manuel Alegre, Duarte de Faria constrói parte da sua infância na ficcional cidade de Alma, em Portugal, na primeira metade do século $\mathrm{XX}$. O discurso memorialístico é erigido, nas próprias palavras do narrador, por meio de um "Tanto quanto me recordo" (ALEGRE, 2009, p. 9) ${ }^{1}$, e, nessa amálgama de lembranças de um período distante - recuperado, analisado e interpretado pelo adulto -, é significativa a importância concedida ao espaço da casa da infância.

Em sua leitura de Alma, Paula Morão (1999) aponta que a casa é um dos núcleos em torno do qual o romance está organizado. No entanto, esse espaço ganha matizes amplos ao longo de texto: ele revela não só uma casa específica, estritamente pessoal e diferenciada, apresentada detalhadamente no quarto capítulo. Uma vez que a memória do narrador, por meio de diversas estratégias textuais, é um "operador do tempo mítico, convertendo a narrativa em muito mais do que a mera história de um universo privado" (MORÃO, 1999, p. 293), a casa encenada está além da construção arquitetônica recuperada pelo narrador.

Já a abordagem de Ana Maria Vilhena aponta que, neste texto de Manuel Alegre, "encontramos essencialmente um espaço e um tempo de prazer e descoberta" (2005, p.357). Essa constatação, alinhada às indicações acima e confrontada com trechos de Alma, proporciona um debate acerca desse espaço da narrativa, relacionando-o com aspectos como os desenvolvidos pelos filósofos Otto Friedrich Bollnow, e seu entendimento de espaço vivenciado, e Gaston Bachelard, e suas análises acerca da relação topofílica do sujeito com o espaço. Nesse cotejo entre texto literário e teorias acerca do espaço, percebe-se que a casa no romance de Manuel Alegre tem esses aspectos de prazer e descoberta - mencionados acima inclusive tensionados.

Para Bollnow, em $O$ homem e o espaço, a casa da infância é a uma espécie de pátria, casa que funciona não só como "um ponto de referência, mas como um território central de todas as relações espaciais" (BOLLNOW, 2008, p. 61). A rememoração de Duarte em Alma, como será demonstrado a seguir, explicita não só isso, mas também o que Bachelard sublinha em A terra e os devaneios do repouso: que por trás da casa natal há uma casa onírica, que responde à desejos e inspirações profundas, de modo que "Ao invés de sonharmos com o que foi, sonhamos com o que deveria ter sido" (BACHELARD, 2003, p. 77). Neste romance de Manuel Alegre, essa nuança de o que deveria ou poderia ter sido tem principalmente a ver com a experiência que algumas das personagens não têm na casa familiar.

\footnotetext{
A partir deste ponto, será explicitado somente o número de página em todas as citações referentes à edição utilizada de Alma.
}

A primeira apresentação detalhada do espaço da casa - o quarto capítulo - já revela um lugar que está além da estrutura física e de relações profundas com o indivíduo: "Dizia-se: a casa. E era como se fosse um castelo, um sítio sagrado, o último reduto" (p. 53, grifos nossos). Ora, o que é isso senão uma casa natal, aquela construída através da onírica, que "é um refúgio, um retiro, um centro. Os símbolos então se coordenam. [...] casa que tem poderes cósmicos" (BACHELARD, 2003, p. 80)? Essas ideias de segurança, sacralidade e de espaço principal do sujeito estão desenvolvidas ao longo de todo romance, seja em relação às personagens principais do texto, como o narrador e seus pais, seja em relação às personagens periféricas.

Após especificar dados arquitetônicos do edifício, ${ }^{2}$ o narrador conclui: "Enfim, era a casa. A casa com seus retratos, seus ruídos, seus silêncios e seus mistérios" (p. 58). À medida que apresenta seu passado, e à medida que apresenta a casa, Duarte de Melo também dispõe, por meio dela ou na encenação das personagens nesse espaço, figuras importantes de sua infância ("retratos"), conflitos familiares ou sócio-históricos ("ruídos"), um grito mudo acerca da condição da mulher (um dos "silêncios") e mesmo situações inapreensíveis à criança, como a morte ou mesmo sessões espíritas naquele local ("mistérios"). Afinal, como Bachelard pondera em A poética do espaço, "Para quem sabe escutá-la, a casa do passado não é uma geometria de ecos? As vozes, a voz do passado, ressoam de formas diferentes no grande aposento e no quartinho" (2008, p. 74). Na casa da infância de Alma, seja na sala de jantar ou no quarto da criança, tem-se a oportunidade de se vislumbrar diversos aspectos acerca de como o sujeito pode habitar um espaço.

Casa é um espaço onde, idealmente, o indivíduo possui um "estância contra o assalto do mundo, para que possa encontrar segurança e paz" (BOLLNOW, 2008, p. 138). Assim como o "castelo" mencionado por Duarte, ela é local de proteção e refúgio. Um exemplo disso é quando o menino, tomado pelo medo da morte, começa "a ter medo de sair de casa, de ficar sozinho, de estar na Escola" (p.46) e refugia-se em seu quarto.

É interessante notar o uso de Escola com inicial maiúscula, marcando mais que um local como qualquer outro, um substantivo comum, mas como um substantivo próprio, uma instituição. Lá ele não estava sozinho, mas, se consideramos a ideia de não lugar como desenvolvida por Marc Augé, a escola é um espaço com natureza diversa de onde ele vive com sua família, e ainda mais de seu quarto: o não lugar, entre outras características,

\footnotetext{
É importante sublinhar que o projeto da casa é atribuído a um dos mais conhecidos arquitetos portugueses do século XX: Raul Lino, cujos trabalhos foram relevantes em uma das concepções de "casa portuguesa".
} 
é o espaço onde os indivíduos não podem se manifestar com profundidade, realizar plenamente desejos ou mesmo transgressões; não é um lugar antropológico porque são locais que são emprestados ao sujeito (AUGÉ, 2012). Ou seja, na escola, talvez diferentemente de em casa, a individualidade - e mesmo a integridade - do sujeito não estaria necessariamente assegurada. Em casa o menino Duarte pode falar do medo e sente que pode se proteger dele, e Bachelard lembra que "sabemos bem que nos sentimos mais tranqüilos, mais seguros na velha morada, na casa natal, que na casa das ruas que só de passagem habitamos" (2008, p. 59). A escola é, em certa medida, um lugar de passagem também.

Ao mesmo tempo, essa casa da infância não era um local isento de conflitos individuais, internos, ou mesmo histórico-coletivos. Na casa da memória habitam principalmente a mãe, Mariana, e a avó, Beatriz, republicanas, e o pai monárquico, Lourenço de Faria, entre os quais o menino Duarte sente-se dividido, devido às posições politicas opostas dos progenitores. Essa coexistência pacífica é possível, como Bollnow (2008) sinaliza, porque a casa como espaço familiar e seu mundo possuem formas distintas para uma convivência em grupo. Afinal, a casa-castelo não é de um só rei, um indivíduo. Assim, a casa da infância de Duarte pode abrigar contradições, conciliar oposições: é um local onde coexistem formas diferentes de encarar o mundo e o até futuros possíveis para Portugal.

Esse lugar, porém, não é só uma fortificação que abriga a família e que protege o menino contra a "coisa preta" (como denomina o medo da morte), ou espaço de conflito e mesmo de resistência política (como acontece com a avó Beatriz, em face à possível captura por opositores). ${ }^{3} \mathrm{Na}$ memória de Duarte, como ele mesmo identifica, ela era um espaço sagrado, e aqui entende-se "sagrado" como nos termos de Mircea Eliade. Em sua distinção entre o espaço profano e o espaço sagrado, em $O$ sagrado e o profano: a essência das religiões, o homem religioso perceberia o espaço total como não homogêneo, mas sim com uma diferenciação entre porções, na qual algumas são mais valorosas que outras. Haveria para o homem arcaico, afeito à sacralidade, o caos da homogeneidade em oposição à existência de um centro organizado, diferenciado, que corresponderia ao espaço sagrado (ELIADE, 2010).

Dentre esses espaços estaria a casa, integrada ao todo, organizada, e como um dos centros possíveis do espaço. Assim, há o território habitado, o cosmos, e o território desconhecido e indeterminado, o caos. Nessa oposição, o homem religioso é desejoso de viver no

O alerta acerca da situação da matriarca está narrada no décimo sexto capítulo. centro, e a casa, um microcosmo, equivaleria ao macro de um espaço sagrado:

Numa palavra, sejam quais forem as dimensões do espaço que lhe é familiar e no qual ele se sente situado - seu país, sua cidade, sua aldeia, sua casa -, o homem religioso experimenta e necessidade de existir sempre num mundo total e organizado, num Cosmos. (ELIADE, 2010, p. 43)

Essa integração entre sujeito, casa e espaço ao redor - um espaço organizado, com partes distintas, mas integrado, um cosmos - é observado tanto quando Duarte fala de sua própria casa mas também quando fala de outra casa importante da sua infância, a da tia Hermengarda. Nesse outro lugar relembrado, do qual também possui boas lembranças, ficam explicitadas essa relação direta do espaço com o sujeito que o habita:

a magia da casa que era inseparável da Tia, do seu olhar, do jeito inconfundível de fixar o chapéu com um alfinete, do modo como lia o Cyrano ou o Só e por vezes ficava um pouco nostálgica a pensar num rei perdido numa batalha num areal distante (p. 193).

A casa da tia também mostra que esse local abarca não só indivíduo, mas também o entorno, em um modo de existir que compreende o sujeito, a casa e o espaço ao redor, todos interseccionados, em consonância com a postulação de Bollnow (2008) de que o sujeito pode habitar o corpo, a casa e o espaço ao redor. Nesse contexto, o filosofo alemão propõe uma definição geral de casa, que seria "cada âmbito fechado que se projeta a partir do corpo, em que o homem possa permanecer e se mover com segurança" (BOLLNOW, 2008, p. 303). Assim, o castelo de Duarte não é só a casa, delimitada arquitetonicamente. Em Alma, o corpo, a casa e o espaço ao redor no qual ele circula com desenvoltura estão, de certa forma, em relação direta: "Também ali estão as minhas raízes, que em certos momentos da minha vida eu via como as raízes grossas do pinheiro que se cruzavam por baixo da casa e de certo modo estavam dentro de nós" (p. 194). ${ }^{4}$ Afinal, como Bachelard sublinha - e a abordagem de Duarte acerca de suas casas da infância confirma -, "A casa vivida não é uma caixa inerte. $\mathrm{O}$ espaço habitado transcende o espaço geométrico" (2008, p. 62).

A explicitação da ideia de enraizamento e intersecção entre esses três espaços no qual vive-se, como aponta

\footnotetext{
4 Apesar de não ser o objetivo do presente estudo, é pertinente notar que as imagens de raiz, de árvore e de madeira, que figuram nesta e na próxima citação do romance, propiciam uma outra abordagem por meio dos estudos bachelarianos: talvez uma análise, por exemplo, do "vegetalismo terrestre" ou "vegetalismo duro" (vide BACHELARD, Gaston. A terra e os devaneios da vontade: ensaio sobre a imaginação das forças. 4. ed. Trad. de Maria Ermantina de Almeida Prado Galvão. São Paulo: WMF Martins Fontes, 2013.)
} 
Bollnow, vem desenvolvida claramente no romance quando o narrador, ao final do texto, retoma o sofrimento de ter de deixar a casa de Alma:

Olhava agora cada canto da casa com se fosse pela primeira vez. Os móveis, as cadeiras, as pratas, a luz e a sombra de certos ângulos, a certas horas, certos ruídos, o estalar da madeira, o bicho roedor do tempo que de noite se ouvia em toda a casa. [...] Eu abria a janela da sala de jantar, olhava o jardim à hora do crepúsculo e sentia o rumor da casa, as suas raízes e a sua perenidade. Estavam em mim, eram a minha própria respiração. Como deixar a casa, a rua, os amigos? (p. 223-224, grifos nossos)

Essa casa do ser, além de proteger e de ser inseparável do sujeito, parte de seu ritmo, como a respiração, também abarca elementos externos a ela. É, ao mesmo tempo, local de reclusão, o "castelo", assim como de conexão com mundo. A casa de Alma é onde muitos chegam e de onde outros partem; como mencionado no quarto capítulo, é espaço que engloba e que está cadenciado com outros espaços: "Naquele tempo o rio e o campo estavam vivos. Ritmavam, como já disse, os ciclos e as estações. E de certo modo faziam parte da casa" (p. 63, grifo nosso).

$\mathrm{Na}$ memória do narrador, a casa aparece como mundo integrado, diferente de um caos. A simbiose entre sujeito, casa e espaço ao redor fica explicita também no contraponto que o narrador faz em relação à experiência de seu pai com a residência, na qual, diferentemente do filho, parece sentir-se um hóspede: "Mas para mim a casa era ali, quase junto ao rio que por vezes invadia a rua, entrava na adega e no jardim e estava, por assim dizer, dentro de nós" (p.59). A casa era dentro dele, e ela algo que estava além de seus alicerces, paredes e telhado. ${ }^{5}$

Essa ideia de uma casa-cosmos de Duarte - integrada, organizada, espaço diferenciado, oposto de um caos traz consigo a ideia de local no qual o sujeito também está enraizado. Os que a habitam estão ligados de modo definitivo e profundo a ela. Isso faz da casa um centro por excelência, o "último reduto" (p.53) que ele menciona como terceira característica da casa.

De modo geral, a casa é o centro do espaço vivenciado do sujeito, centro no qual ele está "enraizado no espaço e ao qual todas suas relações no espaço estão referidas" (BOLLNOW, 2008, p. 133). Casa funciona como um reduto último porque pode proporcionar uma manifestação plena do indivíduo: "a casa é nosso canto do mundo. Ela é, como se diz amiúde, o nosso primeiro universo. É um verdadeiro cosmos. Um cosmos em toda a acepção do termo" (BACHELARD, 2008, p. 24). Dessa maneira, ela existe com tal centralidade e importância para o sujeito

\footnotetext{
5 A relação do pai com a casa familiar é explicitada a seguir.
}

que pode inclusive determinar experiências espaciais posteriores à infância, por exemplo. Quando relembra as sessões espíritas que ocorriam num determinado cômodo da casa, Duarte afirma:

Aquelas sessões assustavam-me muito. E ainda hoje não gosto de passar em grandes corredores sombrios com retratos nas paredes. Como era o corredor sombrio que conduzia à saleta da salamandra. Em todas as outras salas, e também nos quartos, havia fogões. Só ali não. Aquela salamandra negra parecia-me uma boca para não sei o quê. (p. 44, grifo nosso)

Além disso, uma relação determinante com a casa de Alma não era exclusiva ao menino Duarte. Sua mãe, Mariana, a ativista republicana casada com o chefe do lar monárquico, possui com esse espaço uma relação ambígua: por um lado, é seu reduto familiar; por outro, é um lugar ao qual sua atividade está, em certa medida, limitada. Como sua ação no espaço externo é ainda cerceada em alguns âmbitos por sua condição feminina naquele período histórico, a vida doméstica aprisiona suas ambições, isso porque:

Quando a pessoa deixa a porta de sua casa, observa Simmel, "a vida jorra para fora da porta, para fora do enclausuramento da ensimesmação exclusivista, para o ilimitado de todas as direções". E na verdade são as direções de caminhos que, contrapondo-se à equilibrada quietude da vida caseira, obrigam à decisão. $\mathrm{O}$ mundo externo se representa nelas como o âmbito das decisões necessárias. (BOLLNOW, 2008, p. 75)

Mariana não vivia enclausurada em casa, pelo contrário: estava envolvida inclusive nas atividades políticas. No entanto, esse mundo externo, rico de possibilidades e decisões amplas, um campo de ação maior disponível aos homens de sua classe social, não estava completamente acessível à Mariana:

Naquele tempo de fadas do lar, ela ansiava pela cidade, o cosmopolitismo, o risco, a intervenção. Onde outras ensinavam a subserviência, o respeitinho e o cuidadinho, senão mesmo denúncia, ele incitava ao desacordo e à ruptura. E como não tinha espaço, nem cidade, nem batalhas, vivia em guerra consigo mesma. Ninguém percebia certas zangas de minha mãe. Eu creio que era com a rotina, o dia a dia, o rame rame. Por isso é que de vez em quando ela tinha que virar a casa pelo avesso, pôr tudo fora do lugar, bater nos tapetes, arear, esfregar, desarrumar. Era a sua forma de revolta e subversão (p. 188).

Ela ansiava por mais atuação no âmbito externo, o espaço da luta e de embate também, mas sua possibilidade de ação era maior no espaço interno, do repouso, o castelo. Como seu desempenho é principalmente possível neste 
último, a mãe de Duarte agia sobre ele. A duplicidade do espaço em externo e interno, como apontada por Bollnow, ou da dialética entre casa e universo, como sinaliza Bachelard, são limitadas na vida de Mariana. Ela desfruta majoritariamente do aconchego e da proteção da casa, mas não totalmente dos desafios do mundo externo: "O espaço externo é o espaço da atividade no mundo, em que se tem constantemente de superar resistências, e armar-se diante do oponente; é o espaço do desabrigo, dos perigos e da exposição" (BOLLNOW, 2008, p. 139).

A ligação da mãe com a casa é profunda na memória do narrador, e ele chega a estabelecer uma relação direta dela com esse espaço. Sobre uns dos muitos que circulavam por esse local de sua infância, diz: "alguns vagabundos, como o Lince, que não tinha outra referência senão a casa" (p.53). Em um outro capítulo, explicita melhor a ligação de Lince com o lugar:

Vinha e instalava-se, como se tivesse saído na véspera. Creio que ele se considerava da casa. Nunca falava de pai ou de mãe, nem se sabia se tinha irmãos. Talvez ele próprio não o soubesse. A minha mãe era para ele a única referência, a casa, o calor, o pão, o aconchego. Até o ralho (p. 152).

Curiosamente, Mariana condensa as qualidades de uma casa, como as indicadas por Bachelard e por Bollnow: centralidade, proteção, conforto. Já Lourenço de Faria, que era o "chefe de família" (p. 11) - um poder maior na casa -, não percebia aquele local como seu, como próprio:

Meu pai perguntava sempre onde é que queriam que se sentasse. Era uma coisa que me encanitava. Não que ele não soubesse, nem por distracção. Creio que era para marcar distâncias e desse modo significar que aquela não era verdadeiramente a sua casa. Às vezes parecia um hóspede (p. 59).

Essa estrangeiridade do pai em relação ao local fica explicita quando o narrador rememora os passeios de fim de semana a Vilar, lugar onde o pai e seus amigos eram como cavaleiros da Távola Redonda. Diferentemente da casa de Alma, que acolhia as diferenças, na reunião dos cavaleiros o espírito de irmandade atenuava, ou mesmo eliminava, qualquer diferença:

Eu assistia, espantado, à transformação do meu pai. Chegava a Vilar e os olhos brilhavam de outro modo. Como se regressasse de um exílio e de repente estivesse de novo entre os seus. Creio que era isso: aos sábados, em volta daquela mesa, ou depois, ao fogão, na sala de jogos, eles saíam de seus vários desterros e clandestinidades. Vilar era uma pátria, outro tempo, outro lugar, onde se abolia o quotidiano, a vida chata, a contrariedade burguesa dos horários e das profissões (p. 89-90, grifos nossos).
A casa familiar, a casa na qual ele era o chefe, não era o suficiente para o repouso, para o sonho, para a liberdade de Lourenço. Vilar era o espaço sagrado dele, e não a casa de Alma. Como Bachelard observa, por exemplo, acerca dos sonhos com uma cabana primitiva, ele afirma que "desejamos viver em outro local, longe da casa atravancada, longe das preocupações citadinas" (2008, p. 48). É isso que Lourenço de Faria encontra nos finais de semana em Vilar.

Todos esses aspectos levantados acima endossam a seguinte proposta de leitura do romance:

o objetivo de Alma não é tanto o elaborar de uma sucessão de episódios retratando um passado que já morreu, mas o fixar das memórias que constituem um sujeito também historicizado, contextualizado, porém interpretando o factual reconduzindo-o ao eixo central da narrativa, que é a interrogação sobre a identidade do $e u$ nesses anos de formação (MORÃO, 1999, p. 289, grifo da autora).

A casa construída no romance é uma que, por excelência, é o lugar desse $e u$ e de outros com quem ele se relacionou. Ela não funciona só como um mero eixo temático no texto, mas como um local central dessa identidade que narra: parece ter sido central no passado, na infância; porém, pela forma como é revisitado e interpretado, é central ao adulto que rememora-o. A casa da infância está revelada no romance como um dos espaços que precisam ser fixados, registrados, inscritos. A casa não deixa de ser um espaço referencial, mesmo quando exerce o papel de local para ser deixado; ela é inclusive um ponto inicial de onde começam caminhos possíveis.

Dessa maneira, ao mesmo tempo que a casa é um refúgio, um castelo, um espaço de segurança para Duarte, ele também nutre o desejo de deixá-la. O menino, aos olhos do narrador, tem a curiosidade por uma outra liberdade, diversa da proporcionada ao sujeito pelo ambiente domiciliar. Ele também nutre desejo por desafios proporcionados pelo espaço externo, como a mãe o tem. No mesmo capítulo em que a casa da infância tem destaque, lê-se: "Eu tinha uma irresistível atracção pelos ciganos e pelo circo. [...] A minha mãe e a minha avó temiam que eles me levassem. Eu creio que tinha essa esperança" (p. 55). Essa breve menção no quarto capítulo é desenvolvida no décimo terceiro:

Uma velha cigana disse-me, talvez por causa da cor dos olhos: pareces um cigano.

Eu tinha inveja dos ciganos [...]. Não tinham casa, não eram obrigados a ir à escola, não estavam sujeitos a nenhum horário, a nenhuma obrigação. Um dia, Zé Mafra, pai de um ciganito meu amigo disse-me uma coisa lindíssima, nunca mais me esqueci, parece um poema: cigano não tem casa, cigano só tem caminhos. 
Era talvez por isso que eu não resistia a andar com eles: pelo que neles havia de vagabundagem, outros rios, outras terras, outras fronteiras (p. 146, grifos nossos).

A casa, assim como para o pai e para a mãe - apesar de modos diversos - era também elemento do cotidiano aprisionador; liberdade completa seria possível, em determinados casos, fora dela. A repetição do pronome "outro", assim como no trecho destacado acima sobre Vilar, releva o desejo de uma experiência espacial nova, diferente da diária. A ausência de rotina, a busca de uma liberdade maior (no caso da mãe, principalmente) ou de resistência à rotina (no caso do pai - lido pelo filho como uma aspiração a uma vida cavalheiresca), pode ser uma espécie de desejo de ser um wanderer, um flâneur, nos termos de Bollnow:

O homem quer o Wandern, quer sair de seu mundo de sempre, do cotidiano. [...] A pessoa quer caminhar, quer estar a caminho, mas não quer chegar a parte alguma. [...] É a libertação dos esforços e preocupações do cotidiano, o posto entre o trabalho ordenado e objetivo e o Wandern despreocupado e sem dificuldades (BOLLNOW, 2008, p. 122-123).

Apesar dessas tensões em relação à casa, para Duarte, ela é de qualquer maneira um centro no mundo. Centro que, como Bollnow (2008) prevê, possui núcleos internos, como a cozinha, a sala, o quarto. A casa de Alma, de três pisos, com sótão, quartos, salas, cozinha e outras dependências, no texto-memória do narrador possui um cômodo - a sala de jantar - que pode ser considerado um dos eixos dessa casa sonhada:

Era uma sala grande, larga, harmoniosa. Havia nela um não sei o quê, como não vi nunca mais, em nenhuma outra. Nem mesmo nas que tinham sido feitas à imagem e semelhança, em outras casa da vila. [...] um ambiente, um calor, um cheiro próprio, como se a sala de jantar, também ela, tivesse uma respiração e um ritmo. Ou talvez uma alma. Talvez fosse isso. Há sítios, salas, objetos, que se apoderam da alma das pessoas. Há pequenas caixas, em cima das mesas, que podem estar cheias de gente (p. 56, grifos nosso).

A análise de Duarte desse centro explicita não só o fato de essa casa ser quase como um organismo, mas também como se ela contivesse os que passaram por ela, os que não mais estão acessíveis no momento em que a rememora. A tentativa do narrador é a de apreender algo que o escapa. Como sinaliza Bachelard: "Evocando as lembranças da casa, adicionamos valores de sonho. Nunca somos verdadeiros historiadores; somos sempre um pouco poetas, e nossa emoção talvez não expresse mais que a poesia perdida" (2008, p. 26).
No trecho acima, como destacado em outros, ele faz uso do "respirar" e do "ritmar". A casa com toda sua potência figura como um espaço que se aproxima do animado, humanizada: "Enfim, era a casa. A casa com seus ruídos, seus silêncios e seus mistérios. O soalho de madeira que de noite rangia, os móveis muito antigos, de onde por vezes vinha um pequeno estalido. Quase como um gemido" (p.58).

Recuperar, organizar, estruturar ou aferir a memória dessa casa complexa não é sempre fácil ao narrador. Sobre o período do Natal, que está destacado no pequeno décimo quinto capítulo, constata:

Então a casa ficava diferente. Talvez por causa do cheiro do musgo, das luzes a acender e a apagar na árvore e no presépio, talvez porque era Natal e havia um não sei quê no ar, tudo mudava, a casa, as pessoas, o ritmo. $[\ldots]$

Os murmúrios, as cumplicidades, as lembranças. [...] Como recuperar o crepitar da lenha, a luz, as vozes? (p. 158-159, grifos nossos).

Novamente, o ritmo. A casa, como percebe-se ao longo do romance, é um tema recorrente. Duarte de Melo declara: "minha tia e o meu pai transmitiram-me ritmos e temas que para sempre ficaram dentro de mim" (p. 48-49, grifos nossos). Com a tia, quando menino, lia sobre as batalhas míticas e também sobre casas poéticas, tendo em vista a lembrança da abertura ("Intróito") 6 de Pequena casa lusitana: "Então, quando ficávamos assim, derrotados e nostálgicos, Tia Hermengarda declamava uns versos de António Sardinha: Casa do Pedro-Sem e do Encoberto / Casa que tem tudo e não tem nada / Nem mesmo a cinza sobre o lar deserto" (p.192). A casa é um de seus motes. A casa é um dos ritmos de sua memória.

\section{Referências}

ALEGRE, Manuel. Praça da canção. Coimbra: Vértice, 1965.

Alma. 15. ed. Lisboa: Dom Quixote, 2009.

AUGÉ, Marc. Não lugares: introdução a uma antropologia da supermodernidade. 9. ed. Trad. de Maria Lúcia Pereira. Campinas, São Paulo: Papirus, 2012.

BACHELARD, Gaston. A poética do espaço. Trad. de Antônio de Pádua Danesi. 2. ed. São Paulo: Martins Fontes, 2008.

A terra e os devaneios do repouso: ensaio sobre as imagens da intimidade. 2. ed. Trad. de Paulo Neves. São Paulo: Martins Fontes, 2003

\footnotetext{
6 SARdinHA, António. Pequena casa lusitana: sarcasmos, esperanças e elegias. Porto: Civilização, 1937
} 
BOLLNOW, Otto Friedrich. O homem e o espaço. Trad. de Aloísio Leoni Schimid. Curitiba: Editora UFPR, 2008.

ELIADE, Mircea. O sagrado e o profano: a essência das religiões. Trad. de Rogério Fernandes. 3. ed. São Paulo: Editora WMF Martins Fontes, 2010.

MORÃO, Paula. Memória, História e mito em Alma e $A$ terceira rosa, de Manuel Alegre. O Escritor - Revista da Associação Portuguesa de Escritores, n. 13/14, p.288-301, dez. 1999.
VILHENA, Ana Maria. Manuel Alegre e a interminável busca do azul. Lisboa: Dom Quixote, 2005.

Autor:

BRUno MAZOLINI DE BARRos

Pontifícia Universidade Católica do Rio Grande do Sul.

Porto Alegre, RS, Brasil.

brunomazolini@gmail.com

Recebido: 08/05/2018

Aprovado: 08/05/2018 